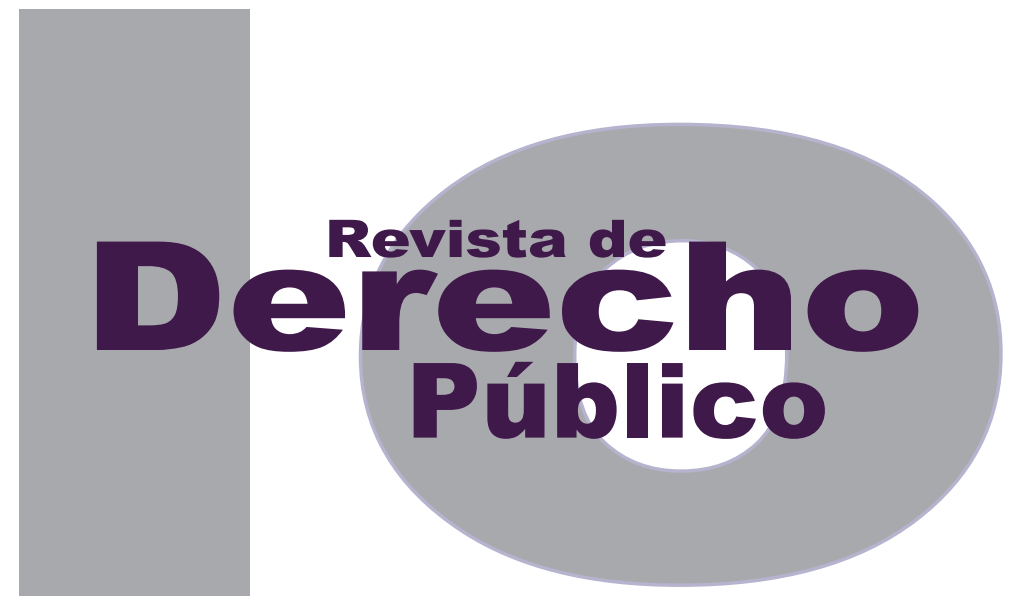

\title{
ENTRE LO CONSTITUCIONAL Y LO CONVENCIONAL: UN ESTUDIO DE LAS FUENTES JURÍDICAS DEL ESTADO COLOMBIANO A PARTIR DE LA SANCIÓN DE INHABILIDAD
}

\author{
HenRy MaURicio Reyes Garcés \\ JuAn SEbastián ARIZA QUINTERO \\ Mario Alberto Amaya SUÁrez \\ Yuliana MARIÑo JaIMES
}

\section{Artículo de reflexión}

DOI: http://dx.doi.org/10.15425/redepub.34.2015.05

Universidad de los Andes

Facultad de Derecho

Revista de Derecho Público N. ${ }^{\circ} 34$

Enero - Junio de 2015. ISSN 1909-7778 


\title{
Entre lo constitucional y lo convencional: un estudio de las fuentes jurídicas del Estado colombiano a partir de la sanción de inhabilidad
}

\section{Resumen}

El reciente desarrollo del control de convencionalidad en la jurisprudencia de la Corte Interamericana de Derechos Humanos genera en los ordenamientos jurídicos un aparente cambio de paradigma frente a las fuentes del derecho y una translación de la supremacía constitucional, lo cual ha provocado debates de dogmática constitucional de amplía trascendencia para la comprensión del derecho en el sistema jurídico colombiano. A partir de lo anterior, el objetivo general de esta investigación fue plantear un criterio hermenéutico que permita solucionar divergencias normativas que surjan entre la Convención Americana de Derechos Humanos y la Constitución Política colombiana, para llegar a una interpretación armónica de ambas fuentes. Desde esta perspectiva, como resultado de una investigación jurídica, y a partir del estudio de la sanción de inhabilidad -caso particular donde colisionan la normatividad interna con la normatividad exterior-, se determina cómo funciona el sistema de fuentes en Colombia, a la luz de la doctrina del control de convencionalidad.

Palabras clave: control de convencionalidad, supremacía, primacía, Convención Americana de Derechos Humanos, Constitución, sanción de inhabilidad.

\section{Constitutional or conventional law: investigation of sources of law based on the study of the inability sanction}

\begin{abstract}
The recent development of the concept of "conventionality control" in the precedent case law of the Inter-American Court of Human Rights generates a transmutation of the sources of law and a translation of the principle of constitutional supremacy in the national legal orders. This has induced an important discussion about constitutional dogmatic which has had a tremendous influence on the understanding of law in the Colombian legal system. Based on these reasons, the main objective of this research was to establish appropriate criteria of interpretation to allow solving regulatory differences between the American Convention on Human Rights and Political Constitution of Colombia, and in this manner achieve a harmonic interpretation of both. From this perspective, this research determines how the sources of law in Colombian legal system work based on the study of the inability sanction-particular case where both legal sources collide.

Keywords: conventionality control, supremacy, primacy, American Convention on Human Rights, Constitution, inability sanction.

\section{Entre o constitucional e o convencional: um estudo das fontes jurídicas do Estado colombiano a partir da sanção de inabilidade}

\section{Resumo}

O recente desenvolvimento do controle de convencionalidade na jurisprudência da Corte Interamericana de Direitos Humanos gera nos ordenamentos jurídicos uma aparente mudança de paradigma frente às fontes do direito e uma translação da supremacia constitucional, o qual tem provocado debates de dogmática constitucional de ampla transcendência para a compreensão do direito no sistema jurídico colombiano. A partir do anterior, o objetivo geral desta pesquisa foi plantear um critério hermenêutico que permita solucionar divergências normativas que surjam entre a Convenção Americana de Direitos Humanos e a Constituição Política colombiana, para chegar a uma interpretação harmônica de ambas fontes. Desde esta perspectiva, como resultado de uma pesquisa jurídica, e a partir do estudo da sanção de inabilidade -caso particular onde colidem a normatividade interna com a normatividade exterior-, se determina como funciona o sistema de fontes na Colômbia, à luz da doutrina do controle de convencionalidade.

Palavras-chave: controle de convencionalidade, supremacia, primazia, Convenção Americana de Direitos Humanos, Constituição, sanção de inabilidade. 


\title{
Entre lo constitucional y lo convencional: un estudio de las fuentes jurídicas del Estado colombiano a partir de la sanción de inhabilidad*
}

\author{
Henry Mauricio Reyes Garcés** \\ Juan Sebastián Ariza Quintero** \\ Mario Alberto Amaya Suárez ${ }^{* * * *}$ \\ Yuliana Mariño Jaimes****
}

\section{SUMARIO}

Introducción - I. PRESUPUESTOS BÁSICOS - II. SANCIÓN DE INHABILIDAD DESDE LA PERSPECTIVA JURÍDICA INTERNA E INTERNACIONAL - III. CRITERIOS HERMENÉUTICOS PARA LA ARMONIZACIÓN DE LA CADH CON LA CONSTITUCIÓN, COMO RESOLUCIÓN DE LA TENSIÓN - IV. CONCLUSIONES - Referencias.

\footnotetext{
* Cómo citar este artículo: Reyes Garcés, H. M., Ariza Quintero, S., Amaya Suárez, M. A., y Mariño Jaimes, Y. (Junio, 2015). Entre lo constitucional y lo convencional: un estudio de las fuentes jurídicas del Estado colombiano a partir de la sanción de inhabilidad. Revista de Derecho Público, 34. Universidad de los Andes (Colombia).

** Abogado, Universidad Industrial de Santander. Estudiante de la Especialización en Responsabilidad y Daño Resarcible de la Universidad Externado de Colombia. Asesor Jurídico de S.C.A.R.E. Correo electrónico maorg098@gmail.com

*** Estudiante de Derecho y Ciencia Política, Universidad Industrial de Santander.

**** Estudiante de Derecho. Universidad Autónoma de Bucaramanga. Correo: mamaya254@unab.edu.co

***** Estudiante de Derecho, Universidad Autónoma de Bucaramanga. Correo: ymarino@unab.edu.co
} 
Introducción

Determinar cómo funcionan las fuentes jurídicas en un ordenamiento es un punto esencial en la producción normativa y en la salvaguarda de los derechos fundamentales, dado que la falta de certeza en la aplicación de normas conduce a escenarios de inestabilidad jurídica que redundan en la vulneración de dichos derechos. Es por esto que la presente investigación adquiere vigencia, pues pretende dilucidar el problema a la luz del control de convencionalidad, desde la aproximación a un caso paradigmático que por su fuerza explicativa permita explicar dogmáticamente cómo, en la actualidad, se armoniza el sistema de fuentes normativas en Colombia.

Así las cosas, se seleccionó el estudio de la sanción de inhabilidad no solo por su actualidad, sino por su particularidad, toda vez que a priori se puede observar una colisión normativa: esto es, en Colombia la sanción de inhabilidad impuesta por una autoridad administrativa es legal, mientras que en el Sistema Interamericano de Derechos Humanos es inconvencional. Por tanto, estudiar esta tensión, y la solución transitoria que se le ha dado, es también esclarecer la ubicación de la Convención Americana de Derechos Humanos (CADH) en nuestro sistema de fuentes, lo cual aporta elementos para entender los principios, instituciones y fundamentos del control de convencionalidad.

A la luz de lo anterior, se ha formulado el siguiente problema jurídico: ¿existe un criterio hermenéutico que permita solucionar divergen- cias normativas entre la CADH y el ordenamiento jurídico colombiano?

De ahí, el objetivo general de esta investigación es plantear un criterio hermenéutico que permita solucionar divergencias normativas entre la CADH y el ordenamiento jurídico colombiano. Esto se concretó con los siguientes objetivos específicos: primero, determinar el alcance del sistema de fuentes jurídicas de un Estado y los controles para hacerlo efectivo, en el caso colombiano. Segundo, determinar la naturaleza de la sanción de inhabilidad para ejercer funciones públicas a la luz de Constitución y de la Convención. Y tercero, explicar los criterios hermenéuticos para interpretar la Convención dentro del orden jurídico colombiano.

La presente es una investigación jurídica o artículo de reflexión, por tanto, el método que utiliza para analizar su objeto de estudio es teóricohermenéutico, abordando textos especializados junto a fuentes normativas con una perspectiva crítica y analítica. En ese orden, el paradigma desde el que se estudian dichas fuentes deja de lado las visiones tradicionales sobre este tipo de investigaciones, puesto que se centran en el derecho como un ente abstracto, sin concebirlo como una norma con aplicación en la realidad, para asumir una visión holística de la epistemología del derecho, donde este se concibe como un concepto que se construye al aplicarse (Witker, 2008). En ese hilar de ideas, los métodos que se usaron para acercarse al fenómeno le dan una connotación jurídica, sin que la investigación deje de estudiar el escenario en el cual la norma se desarrolla por medio de la jurispru- 
dencia. Así las cosas, la investigación contó con tres momentos que se dieron de forma simultánea: apropiación de fuentes, sistematización de conocimiento y producción de conocimiento. Etapas que se concretaron en el cuerpo del trabajo, el cual, de suyo satisface los objetivos específicos planteados y, como un todo, da solución a la pregunta de investigación.

El texto se divide en tres partes: inicialmente, se determina el alcance del sistema de fuentes jurídicas en el caso colombiano, con la finalidad de establecer los presupuestos necesarios sobre los que pretende tener incidencia la investigación planteada; seguidamente, se precisa la naturaleza de la sanción de inhabilidad a la luz de la Constitución y de la Convención, para encontrar si realmente se está frente a una colisión normativa; finalmente, se explican los criterios hermenéuticos idóneos para interpretar la Convención dentro del orden jurídico colombiano, lo que permitirá construir un marco conceptual del cual se pueda dar una respuesta, así sea tímida, a la situación problema.

\section{PRESUPUESTOS BÁSICOS}

El derecho se comprende como la sumatoria de ciertos productos sociales, con la característica de tener fuerza vinculante o normativa para todos los miembros de una sociedad, y, por tanto, con efectos directos en la realidad (Barragán, 2013, pág. 14). Empero, para que ello se dé es necesario que sea un producto jurídico -condición que le da validez a la norma (Mejía Quintana, 2005)-, evento que solo se cumple al pro- venir de una fuente de derecho legítima, y ser producido por un sujeto dotado de capacidad para crear normas. Con esto se hace referencia a conocer que algo es derecho por su fuente (Ross, Muñoz, Prada y López, 2007, pág. 355).1

Al indagar por la fuente primigenia del derecho en un ordenamiento jurídico, es decir, aquella que determina cuáles son las fuentes del derecho y qué criterios hermenéuticos deben usarse para sistematizarlas, se encuentra que en última instancia este surge de "la correlación existente dentro de un ordenamiento jurídico" (Ross et al., 2007). En ella se establece, por una parte, un sistema de enunciados normativos que expresan una función que tipifica conductas humanas y como consecuencia de ellas un tipo específico de sanción impuesta bajo una metodología epistemológica; por la otra, una comprensión social de dichos enunciados, que surge de la totalidad de acciones individuales de los miembros del ordenamiento jurídico (Ross et al., 2007). "Este sistema de doble función que se ha entendido como fuente de derecho tiene un contenido material: la expresión de normas jurídicas" (Aguiló Regla, 2000), que surgen con una propiedad determinante.

Por tanto, de la correlación sistema-realidad emanan las instituciones jurídicas, en particular, la Constitución como norma fundamental de cualquier ordenamiento, que para el tema que nos ocupa, según Garrorena Morales (2001) es

\footnotetext{
Al respecto, Mejía Quintana establece una distinción entre legitimidad, como un concepto apoyado en la moral; validez, basada en el mismo derecho; y eficacia, como el logro de los objetivos que las normas se ponen de presente en la realidad.
} 
la que a través de decisiones constitucionales fundamentales (pág. 126) fija quiénes son los únicos sujetos que pueden crear normas, en qué tipos normativos han de formalizarlas y a qué reglas básicas han de atenerse para producirlas (pág. 178). De igual forma, la Constitución en su carácter de norma suprema, y teniendo presente que la producción normativa dentro de cualquier Estado es colosal, determina criterios hermenéuticos para estructurar el sistema normativo, de forma tal que en la solución de problemas concretos un operador normativo pueda actuar frente a vacíos o colisiones entre normas de igual nivel jerárquico, lo que le permite a la autoridad pertinente encontrar o elegir la norma que dé una solución útil al caso que se ha puesto bajo su conocimiento.

Lo anterior evidencia la característica más importante de la Constitución, entendida como un todo: el hecho de que posee la cualidad de tener supremacía dentro de un ordenamiento jurídico; por esto se "alude nada menos que a la condición misma de la constitución como norma que funda o crea a la propia comunidad (...) esta relación se da entre la constitución y el resto del Derecho" (Garrorena Morales, 2011, pág. 85). Lo anterior es una premisa desde la que, como presupuesto necesario, parte la investigación.

El problema del establecimiento de un sistema de fuentes, necesariamente supera las fronte-

2 Garrorena Morales explica que Carl Schmitt define las decisiones políticas fundamentales como aquellos aspectos básicos del sistema constituido, y la especial atención que dentro de este se presta a las calificaciones constitucionales del Estado, es decir, a "aquellas adjetivaciones del mismo con las que la Constitución intenta identificar a éste en sus opciones matrices". ras estatales. La búsqueda de criterios de jerarquización e interpretación normativa encaminados a la armonización de las relaciones internacionales, ha sido una necesidad que se ha satisfecho en la medida en que esta se ha hecho más compleja, tornándose en una construcción inacabable que se ha movido en un contexto dominantemente crítico. No obstante, esta necesidad ha encontrado en el Estatuto de la Corte Internacional de Justicia una respuesta que institucionaliza el sistema de fuentes, consiguiendo de forma más acertada proponer un referente común al derecho internacional en su artículo 38 (Organización Naciones Unidas [ONU], 1945), y de conformidad con este se abordan las fuentes del derecho internacional.

Inicialmente, la costumbre puede identificarse como fuente primaria del derecho internacional, pese a su pérdida de terreno frente a la sofisticación y univocidad del derecho escrito. Esta, tiene una fuerte capacidad integradora de la comunidad desde el punto de vista normativo. De igual forma, los principios generales del derecho, valores éticos y políticos que alimentan los ordenamientos jurídicos de los Estados, funcionan como pilares ideológicos y a la vez como instrumentos hermenéuticos; son fuente del derecho internacional en la medida en que una cantidad considerable de ordenamientos los apliquen, siendo así principios constitutivos de estos.

Para el tema de interés tienen especial trascendencia las decisiones judiciales y los convenios: las primeras tienen la capacidad de unificar la administración de justicia y el derecho interna- 
cional, lo que dota a los Estados de criterios interpretativos de los convenios, que en sí mismos son generadores de obligatoriedad, toda vez que desarrollan los catálogos de derechos y deberes por ellos suscritos. Aunado a lo anterior, teniendo en cuenta el requisito de agotamiento del derecho interno, se encuentra que las decisiones de la Corte Interamericana de Derechos Humanos, a su vez, crean en los ordenamientos internos una función y un compromiso de desarrollar su interpretación conforme al criterio de la Corte (García Sayán, 2009); de este modo sus decisiones judiciales se imponen como una manera de introducir criterios de interpretación, y de incorporar la normatividad internacional en los sistemas jurídicos de los Estados. Respecto a los segundos, los convenios, estos son la positivización del derecho internacional, materia sobre la cual se ha establecido una normatividad útil, plasmada en la Convención de Viena sobre el derecho de los tratados.

Alrededor de los tratados internacionales surge una adversidad lógica y jurídica con relación a la vinculatoriedad del Estado, y al derecho internacional. Desde una posición contractualista, la solución parece sencilla: el Estado se obliga en virtud del convenio en sí - pacta sunt servanda-; sin embargo, realmente y en contraposición a lo anterior, la obligación del Estado como sujeto de derecho internacional, en ausencia de una instancia legislativa internacional, nace de dos aspectos: primero, del derecho nacional, por lo cual el Estado, entendido como el sistema jurídico en unidad, no tiene una vinculación posible más allá de la propia al ordenamiento interno que es modificable unilateralmente; se- gundo, una obligación moral hacia los convenios internacionales (Ross et al., 2007).

Las fuentes del derecho internacional se hacen vinculantes en un ordenamiento jurídico a través del procedimiento de ratificación de los tratados, regulado en la legislación colombiana de modo tal que involucra a las distintas ramas del poder público, en una triada constitucional armónica. Su nivel de fuerza normativa -el lugar que ocupa dentro del sistema de fuentes de cada ordenamiento- se establece, por la misma vía, a través de una institución jurídica determinada, proceso conocido como internacionalización del derecho constitucional, "que busca que las normas internacionales ocupen un lugar definido dentro de los órdenes jurídicos" (Quinche Ramírez, 2009). Colombia concretó este fenómeno en la figura del bloque de constitucionalidad, y determinó un procedimiento de tipo dualista para los tratados que versen sobre derechos humanos, con la finalidad de otorgarles el carácter de fuente del derecho.

Paralelo a este proceso, se desarrolla el de constitucionalización del derecho internacional que extiende los instrumentos de protección, al igual que los mecanismos de control y sujetos encargados de estos, favoreciendo así la eficacia de los tratados y en últimas la protección integral de los derechos humanos (Brewer-Carías y Santofimio Gamboa, 2013).

El bloque de constitucionalidad "como metáfora y como concepto, permite comprender que la Constitución colombiana no se agota en los 380 artículos de su texto, sino que abarca otros com- 
ponentes que son también normas constitucionales" (Quinche Ramírez, 2009, pág. 196), cuya aparición responde a la necesidad de un control eficaz de la actividad estatal, que redirija a la protección de derechos humanos. De ahí surgió la necesidad de una figura procesal que garantice dicho control, y que se ha decantado dogmática y jurisprudencialmente en la categoría "control de convencionalidad". Esta adquiere su justificación en la teleología que manejan tanto la CADH como la Constitución, donde el respeto por los derechos fundamentales, la preeminencia del derecho y los principios del Estado democrático (Brewer-Carías y Santofimio Gamboa, 2013, pág. 12) son una triada necesaria para la legitimación del Estado.

Sin embargo, el quid del asunto, al tratarse de comprender el control de convencionalidad y su incidencia en los órdenes jurídicos internos, subyace en la determinación de la fuerza normativa de la CADH. Lo esbozado plantea un complejo problema jurídico con referencia a las fuentes del derecho: ¿la asunción del control de convencionalidad indica una traslación del principio de supremacía de la Constitución?

La visión de la supremacía de la CADH es señalada por la jurisprudencia de la Corte Interamericana de Derechos Humanos (Corte IDH), al determinar que los Estados parte están obligados a armonizar su ordenamiento jurídico con su normativa de protección, teniendo para este fin el deber de suprimir acciones que violen su articulado o de expedir normas y realizar prácticas que permitan su fomento y efectiva protección (Lori Berenson Mejía vs. Perú, 2004; Masacre de Mapiripán vs. Colombia, 2005), sometiéndose de no ser así, a la posibilidad de que el Estado sea declarado responsable internacionalmente.

Dicha doctrina, creada por la Corte IDH, consiste en un acto de revisión de la correspondencia entre normas nacionales y la CADH junto a la exégesis que la Corte IDH hace de este instrumento. Esta doctrina se sustenta en: el principio de buena fe respecto al cumplimiento de las obligaciones internacionales; el principio de "efecto útil” de los tratados internacionales, contenido en el artículo 2 de la CADH; y en el artículo 27 de la Convención de Viena sobre el derecho de los tratados, que prohíbe la invocación del derecho interno como argumento para incumplir las disposiciones de un tratado (Sagües, 2010).

Existen dos tipos de control de convencionalidad: inicialmente es la Corte IDH, como máximo intérprete del pacto, quien en sede internacional tiene la competencia para realizarlo. Posteriormente, en distintos fallos (Almonacid Arellano y otros vs. Chile, 2006; Trabajadores Cesados del Congreso (Aguado Alfaro y otros) vs. Perú, 2006), la Corte IDH otorga la competencia también a los jueces nacionales, los cuales deben realizar el control de convencionalidad ex officio; a estas dos modalidades, respectivamente, se les ha llamado control concentrado y control difuso de convencionalidad (Ferrer, 2010). El carácter ex officio del control de convencionalidad indica que en cualquier tipo de proceso los jueces deben emitir sus decisiones conforme a la Convención, lo que significa una traslación de un sistema dispositivo a uno parcialmente inquisitivo. Esto se aplica en ambas facetas del control: 
respecto a la primera, surge una obligación de revisar todas las decisiones desde la perspectiva de la Convención para evitar que incurra el Estado en responsabilidad internacional; frente a la segunda, la Corte IDH debe revisar la posible violación de otros derechos consagrados en la Convención, aun cuando no hayan sido traídos a colación por las partes.

En cuanto a los efectos del control de convencionalidad se ha señalado que, una vez realizado el respectivo análisis de confrontación normativa y declarada la inconvencionalidad de una norma interna, se configuraría una causal de invalidez de la norma acusada. Esto conlleva a la inaplicación por parte de la Corte IDH de la norma interna con efectos interpartes en un caso concreto, lo cual no implica que la norma de suyo sea derogada, sino que nace una obligación para el Estado de modificar su ordenamiento ajustándose a los términos de la CADH (Sagües, 2010). Esto podría denominarse una violación simple de la Convención, puesto que la decisión interamericana no implica una abrogación automática de la norma local, dado que es el país quien debe cumplir con el pronunciamiento regional, so pena de incurrir en responsabilidad. Aunado a lo anterior, la Corte IDH frente a delitos de lesa humanidad, por ejemplo en los casos Barrios Altos vs. Perú; Tribunal Constitucional vs. Perú y La Cantuta vs. Perú, se comportó como un verdadero Tribunal Constitucional, declarando inaplicables en todo el país y con efecto erga omnes las leyes de amnistía dictadas en Perú (Hitters, 2009).

De igual forma, señala Sagües (2010) que, si el juez tiene autoridad para derogar una norma interna por ser esta inconstitucional, podría entonces eliminar por analogía una norma inconvencional, lo que produciría efectos erga omnes.

En Colombia, la Corte Constitucional (CConst.) ha reconocido el carácter vinculante de la CADH y de la jurisprudencia de la Corte IDH. Sin embargo, ubica la CADH al mismo nivel de la Constitución, en virtud del principio de supremacía de la Carta Política (Quinche Ramírez, 2009). De ello se concluye que la Corte Constitucional hace una interpretación de los instrumentos que integran el bloque para realizar un control de constitucionalidad y no un control de convencionalidad, por no ser juez competente de la CADH (CConst., C-941/2010).

Junto a lo anterior, un aspecto esencial es que dentro de las normas sometidas al control de convencionalidad también se incluyen normas constitucionales, como ocurrió en el caso La última tentación de Cristo vs. Chile, de 2001, donde se afirma que "la responsabilidad internacional del Estado puede generarse por actos u omisiones de cualquier órgano de este, independientemente de su jerarquía, que violen de la CADH". Lo que podría indicar que la CADH es superior a las normas de jerarquía constitucional, y por ello la soberanía se ve afectada debido a que el objetivo del control de convencionalidad es determinar la invalidez de una norma local a la luz de la CADH (Jinesta, 2012). Empero, al observar que la Corte Constitucional colombiana pese a que ha aceptado la jurisprudencia de la Corte IDH como criterio hermenéutico relevante al momento de examinar la validez de una norma, no ha aceptado su carácter vinculante; de 
lo cual se puede concluir que en ordenamientos jurídicos como el colombiano la doctrina del control de convencionalidad plantea cambios relevantes en el pensamiento jurídico, referentes a las fuentes del derecho.

\section{SANCIÓN DE INHABILIDAD DESDE LA PERSPECTIVA JURÍDICA INTERNA E INTERNACIONAL}

La potestad disciplinaria del Estado colombiano tiene un origen iusfilosófico en la base fundante del ordenamiento jurídico: la Constitución Nacional (CN). De acuerdo con el artículo 6 de la Carta Fundamental de 1991, los funcionarios públicos tienen una responsabilidad categóricamente distinta de la del resto de los ciudadanos, ya que no solo responden por infringir la Constitución y las leyes, sino que también lo hacen respecto del desempeño de sus funciones -ya sea por omisión o extralimitación-; de la misma manera, el artículo 123 determina el deber de cumplimiento de los reglamentos como garantía del desempeño de dichas funciones, y el artículo 124 fija la potestad legislativa para determinar la responsabilidad de los funcionarios públicos. En ese orden de ideas, desde el principio de legalidad se fundamenta una cláusula especial de sujeción, como una manera de garantizar el correcto desarrollo de la función pública.

La potestad disciplinaria es la salvaguarda de la moralidad de los funcionarios públicos y del cumplimiento de los deberes funcionales, es decir, su orientación, a pesar de provenir del ius puniendi gubernativo, no tiene como fin úl- timo la sanción al sujeto infractor, ${ }^{3}$ sino que es un medio para garantizar el correcto desenvolvimiento de la función pública, cuyo fin último es el interés general y los cometidos estatales (CCons., C-028/2006).

Lo anterior permite comprender que por ser un régimen especial de responsabilidad también tiene uno especial de imputación, de ahí que las conductas reprochables derivadas de esta responsabilidad no necesariamente coincidirán con las descritas en otros regímenes, verbigracia el régimen de responsabilidad penal.

Se ha precisado la teleología de la sanción disciplinaria dentro del orden jurídico colombiano como la de "encauzar o dirigir la conducta de sus destinatarios específicos, vinculados por las relaciones especiales de sujeción, dentro de un marco de parámetros éticos que aseguren la función social que cumplen dentro de un Estado social y democrático de derecho" (Gómez Pavajeau, 2011). En tal género se encuentra la sanción de inhabilidad que cumple de acuerdo con Trayter (1992) una función de prevención especial de carácter positivo y negativo. Respecto del primer carácter, la sanción de inhabilidad funge como un medio de educación para los servidores públicos, y su tipificación tiene la cualidad de motivarlos a abstenerse de incumplir en forma gravísima sus deberes funcionales; sobre el segundo, se entiende que la sanción "consiste en impedir u obstaculizar la repetición de la falta por parte de quien ya la cometió y tiene lugar precisamente a través de la represión o escar-

3 La sanción al infractor es de carácter accesorio a la naturaleza de la potestad disciplinaria. 
miento resultante de la ejecución de la sanción" (pág. 265), en otras palabras, es impedir que alguien que ha demostrado su ineptitud o corrupción en el desarrollo de funciones públicas afecte nuevamente el cumplimiento de un rol de tan honda importancia social.

Ahora bien, el límite de esta sanción se halla en los siguientes principios: debido proceso, legalidad, proporcionalidad y razonabilidad. Sobre el primero de los mentados, es claro que para la imposición de cualquier sanción el Estado, en cabeza de su operador disciplinario, debe surtir todos los escaños procesales que el legislador ha establecido.

De acuerdo con el segundo, el principio de legalidad, la sanción disciplinaria debe "estar previamente consagrada en el texto de una ley expedida por el Congreso de la República" (CConst., C-1090/2010). Cabe aclarar que la tipificación de las sanciones disciplinarias se hace a través de criterios de configuración establecidos por el legislador, esto es, señalar "cuáles son las sanciones imponibles y, en abstracto, dada la naturaleza de las mismas, de acuerdo a la calificación de la falta y su gravedad, señalar un marco punitivo" (Gómez Pavajeau, 2011, pág. 528). En concreto, respecto de la sanción de inhabilidad, el legislador ha dotado de una discrecionalidad moderada al operador disciplinario para que determine la cuantificación de la sanción.

Respecto del principio de proporcionalidad, se tiene que la sanción de inhabilidad por ser de carácter fijo lo satisface de suyo; quiere decir lo anterior que el legislador al establecerla ha he- cho en su ejercicio legislativo una ponderación de la afectación del bien jurídico vulnerado con la satisfacción del bien protegido, y la ha encontrado acertada, por ende su aplicación se vuelve obligatoria para el operador disciplinario toda vez que "se atribuye directa e individualmente una sanción a cada infracción" (Nieto, 1994, pág. 347).

En cuarto lugar, con referencia al principio de razonabilidad, la motivación también juega un papel sustancial, pues a través de ella el operador disciplinario debe garantizar que el análisis lógico que dio al momento de tomar una decisión pueda ser reconstruido por cualquier persona que estudie el fallo.

En suma, la sanción de inhabilidad se concreta como un medio idóneo para la satisfacción del interés general y los fines que persigue el Estado, toda vez que se concreta en una herramienta para reparar el ejercicio incorrecto de funciones públicas, en particular de la función administrativa. Lejos de ser arbitraria, la sanción de inhabilidad encuentra claros límites en la legalidad que establece requisitos procedimentales y argumentativos para su imposición.

Desde el punto de vista internacional la naturaleza jurídica de la sanción de inhabilidad toma matices diversos, de tal suerte que se evidencia una contraposición a los postulados del derecho interno colombiano. En relación con esto, la CADH regula de manera expresa la restricción de los derechos políticos ${ }^{4}$ en su artículo 23.2 así:

Convención Americana de Derechos humanos, artículo 23.1: Todos los ciudadanos deben gozar de los siguientes derechos y oportunidades: a. de participar en la dirección de los asuntos públicos, direc- 
"La ley puede reglamentar el ejercicio de los derechos y oportunidades a que se refiere el inciso anterior, exclusivamente por razones de edad, nacionalidad, residencia, idioma, instrucción, capacidad civil o mental, o condena, por juez competente, en proceso penal".

La visión convencional, de acuerdo con lo anterior, es eminentemente restrictiva, y fundándose en sus principios de protección a los derechos humanos, únicamente le atribuye la potestad de restringir los derechos políticos al rigor de un juicio en materia penal. Esta corriente considera que la sanción de inhabilidad, por la importancia de los derechos que limita en los Estados democráticos, debe ser de ultima ratio (Noguera, 2011). Tal apreciación es compartida por Zaffaroni y Risso (2009), quienes consideran que la sanción de inhabilidad, como una medida penal, se suele esconder bajo "el manto del derecho administrativo o político" (pág. 726), con el objetivo de privar a una persona de todas las garantías que ofrece el derecho penal, cosa que en la actualidad resulta inadmisible.

Tal posición no contrasta con la iniciativa de la comunidad internacional, enfocada a generar instrumentos útiles ante las amenazas que la corrupción genera para la estabilidad, legitimidad y seguridad de las instituciones de los Estados democráticos.

tamente o por medio de representantes libremente elegidos; $b$. de votar y ser elegidos en elecciones periódicas auténticas, realizadas por sufragio universal e igual y por voto secreto que garantice la libre expresión de la voluntad de los electores, y c. de tener acceso, en condiciones generales de igualdad, a las funciones públicas de su país.
Dentro de los instrumentos internacionales que comprenden la mencionada sanción, se encuentra la Convención de las Naciones Unidas contra la Corrupción. Este tratado considera que la imposición de una sanción debe ser consecuente con la gravedad del comportamiento y permite que las sanciones varíen según el ordenamiento jurídico del Estado parte. Sin embargo, la Convención exige que ciertos comportamientos sean tipificados como "delito penal", en tal caso, se permite que una sanción penal pueda ir acompañada de una sanción de carácter no penal (Oficina de las Naciones Unidas contra la Droga y el Delito, 2010).

Esta discrepancia, ya en el panorama internacional, ha sido asunto litigioso para la Corte IDH que se ha pronunciado en relación con la restricción de los derechos políticos en varias sentencias, ${ }^{5}$ entre ellas cabe citar el caso López Mendoza vs. Venezuela, en donde considera que la restricción a estos derechos no puede ser llevada a cabo por una autoridad diferente a un juez penal, el cual debe ajustar su decisión al principio de proporcionalidad.

A partir de lo anterior, se puede evidenciar que existe una colisión normativa entre el ordenamiento interno desde la potestad disciplinaria del Estado colombiano y los modos aceptables para restringir derechos políticos de acuerdo con la $\mathrm{CADH}$, puesto que se regula una institución jurídica igual de maneras diversas.

\footnotetext{
$5 \quad$ Al respecto se pueden revisar los siguientes casos: Yatama vs. Nicaragua, sentencia de 23 de junio de 2005 y Castañeda Gutman vs. México, sentencia de 6 de agosto de 2008.
} 
Frente a este conflicto, la Corte Constitucional ha realizado una interpretación sistemática que pondera la norma convencional con las normas constitucionales sobre inhabilidad originadas en la potestad disciplinaria (C-028/2006, H. Sierra), sin embargo, esta interpretación en comparación con el caso López Mendoza vs. Venezuela, respecto de los argumentos de la Corte IDH, no sería suficiente y el Estado colombiano continuaría violando la CADH.

La acción de control de convencionalidad deja al ordenamiento interno a la deriva entre dos posibilidades: la inconvencionalidad de la sanción de inhabilidad desde la potestad disciplinaria del Estado y la declaratoria de responsabilidad internacional contra el Estado colombiano. En la primera hipótesis, el ordenamiento interno no podría tener una sanción efectiva para salvaguardar la función pública cuando la falta no se circunscribe a un injusto penal, lo cual arriesga la moralidad en la función pública y el interés general; esto pondría en entredicho un pilar constitucional, como es el principio de legalidad del que se deriva la cláusula especial de sujeción. El escenario que ofrece la segunda posibilidad, es que el Estado colombiano sea declarado responsable internacionalmente por violación a la Convención y se pondría en entredicho la permanencia estatal en dicho pacto.

Esta problemática nos expone que los tratados internacionales pueden estar ideológicamente relacionados con los fines del Estado y la protección de los derechos fundamentales. Surge, de lo anterior, una dicotomía entre las instituciones jurídicas y los modos de salvaguardar los dere- chos humanos, que en últimas puede amenazar instituciones beneficiosas para los ordenamientos internos.

\section{CRITERIOS HERMENÉUTICOS PARA LA ARMONIZACIÓN DE LA CADH CON LA CONSTITUCIÓN, COMO RESOLUCIÓN DE LA TENSIÓN}

Hasta aquí se evidencia una colisión normativa entre la Constitución y la $\mathrm{CADH}$, lo cual genera una tensión que debe ser resuelta a través de un ejercicio de hermenéutica normativa, para determinar la posición que ocupa esta última dentro del orden jurídico colombiano en virtud del control de convencionalidad, y explicar así qué tipo de norma seleccionará el operador jurídico ${ }^{6}$ para fundamentar el ejercicio de aplicación normativa en el caso de la sanción de inhabilidad para ejercer derechos políticos.

Respecto de la interpretación de los tratados se han utilizado diversos criterios que responden a una necesidad en una situación de hecho específica, pero que frente al control de convencionalidad se hacen insuficientes, toda vez que no logran explicar el fundamento de la declaración de responsabilidad internacional por normas de orden constitucional, o por leyes e instituciones jurídicas declaradas válidas por el Tribunal Constitucional interno.

6 Por este se hace referencia tanto al legislador cuando fundamenta su ejercicio legislativo, como a los jueces cuando seleccionan la norma que les permite resolver un caso concreto. 
Entre los criterios que se han establecido para interpretar sistemáticamente la CADH se cuentan: el jerárquico, el principio pro homine, el de progresividad y de utilidad de los tratados. Sobre el criterio jerárquico de interpretación normativa, es claro que en su virtud, frente a una misma regulación por parte de dos normas distintas, se ha de preferir aquella con mayor nivel normativo. Este criterio se ha utilizado por distintos doctrinantes ${ }^{7}$ como herramienta para explicar el control de convencionalidad y su efecto sobre los ordenamientos jurídicos, afirmando la supremacía de la CADH. Pese a ello, dos argumentos le quitan la entereza a este planteamiento: primero, en Colombia la figura del control de convencionalidad no se traslada automáticamente, pues como lo ha indicado la Corte Constitucional, los análisis que en su virtud se hacen deben tener en cuenta el ordenamiento jurídico interno, especialmente las interpretaciones de las altas cortes (C442/2011); segundo, y más trascendental aún, es que la supremacía de la Convención palidece ante la supremacía constitucional, pues aquella carece de las características de que ha investido el constituyente primario a la segunda, verbigracia: su rigidez -el estricto procedimiento determinado para su modificación frente al procedimiento, mucho más laxo, de denuncia del tratado-; y su carácter de norma suprema, expresamente enunciada en el artículo 4 de la Constitución.

Así mismo, el principio pro homine, como criterio de interpretación, se circunscribe al objeto mismo de los tratados sobre derechos humanos,

7 Este criterio se ha utilizado por distintos doctrinantes, entre los que se cuentan: Brewer Carias, Sagües, Hitters y Ferrer Mac-Gregor. estableciendo un criterio de interpretación que indica al operador jurídico acudir a las interpretaciones más favorables a la hora de reconocer derechos protegidos, y de manera inversa cuando se trate de restringirlos (Pinto, 1997).

Lo anterior guarda relación con el principio de progresividad, el cual indica que en materia de protección de derechos humanos los Estados no pueden tener regresiones, aun en virtud de una disposición convencional. Este principio implica, por su contenido, una obligación particular del Estado de no ir en contra de los derechos ya reconocidos (Bustillo Marín, 2011).

Los anteriores principios no logran la resolución de la tensión normativa planteada, en primer lugar, porque a pesar de conseguir la determinación de una norma aplicable a una situación concreta, no pueden, en caso de existir dos interpretaciones diversas, establecer quién define cuál es la más favorable a la protección de los derechos humanos, y tampoco ofrece una ponderación real entre los derechos protegidos y el interés general.

Por otra parte, el principio de utilidad de los tratados se fundamenta en el cumplimiento de los cometidos de la norma internacional para que sean eficaces y su objeto sea desarrollado. De aquí surge la obligación de los Estados parte de adecuar el derecho interno a los tratados internacionales en materia de derechos humanos. Desde este punto de vista, ante el problema planteado, se restringe a un simple incumplimiento del Estado de las obligaciones suscritas, sin explicar la posición normativa de la CADH. 
El problema de armonizar fuentes internas y externas de derecho no es nuevo en los ordenamientos jurídicos, por el contrario, si se hace un estudio de derecho comparado se puede encontrar que en Europa el Tribunal de Justicia de las Comunidades ha sentado una doctrina que ha sido útil para resolver la tensión entre las diversas normatividades, esto es: el principio de primacía del derecho internacional y de competencia normativa, que puede ser útil a la hora de abordar y explicar el efecto que tiene sobre el sistema fuentes el fenómeno del control de convencionalidad. Sin embargo, dicha doctrina debe trasladarse para efectos interpretativos al orden jurídico colombiano, y particularmente, para los sistemas de protección regional de derechos humanos, toda vez que ha sido sentada para una comunidad internacional que se ha formado con la cesión de soberanía por parte de los Estados miembros, ${ }^{8}$ y no para la protección de derechos fundamentales.

Ahora bien, el derecho comunitario se presenta como un ordenamiento jurídico autónomo a los Estados miembros, empero, al mismo tiempo este se integra a los ordenamientos nacionales que lo han ratificado a través de distintas figuras jurídicas que les otorgan nivel normativo, adquiriendo una eficacia directa: "Estos caracteres, relacionados entre sí, nos ofrecen la imagen de

8 Es explicativo el caso de la Constitución española que clasifica en dos los tipos de tratados que puede ratificar: en su artículo 93 establece aquellos que significan la sesión de soberanía, mientras que en su artículo 94 establece los demás tipos de tratados, donde se enuncian en su literal c: "Tratados o convenios que afecten a la integridad territorial del Estado o a los derechos y deberes fundamentales establecidos en el Título l". De tal forma que en el sistema europeo, al menos para el caso español, la Convención Europea de Derechos Humanos no significa cesión de soberanía, como sí lo significa el Tratado de Lisboa. un sistema jurídico introducido en los ordenamientos de los Estados miembros para ser uniformemente aplicado en ellos conservando, al mismo tiempo, su carácter de sistema autónomo" (Alegre Martínez, 1994).

Esta doctrina fue desarrollada por el Tribunal de Justicia de las Comunidades en la sentencia del caso Flaminio Costa contra E.N.E.L. (Costa) ENEL) de 15 de junio de 1964, donde establece "la imposibilidad para los Estados de hacer prevalecer, contra un ordenamiento jurídico aceptado por ellos sobre una base de reciprocidad, una medida unilateral ulterior" y ratificada en la sentencia "Simenthal" de 9 de marzo de 1978, donde clarifica que la obligación de los jueces de inaplicar la ley interna en virtud del tratado no puede quedar supeditada a la resulta de ningún proceso constitucional.

Trasladando lo anterior al sistema regional de protección americano de derechos humanos, se puede observar cómo a través de las categorías estudiadas -especialmente el control de convencionalidad-, este ha adquirido los mismos caracteres, planteándose la posibilidad de que en Colombia exista, como en España, un "ordenamiento de ordenamientos", o un ordenamiento trabado en la convergencia de dos subsistemas de producción normativa (Garronera Morales, 2011, pág. 180). Exponer las cosas así permite establecer un marco para solucionar la tensión normativa, toda vez que desde esta perspectiva se puede justificar la declaración de responsabilidad de los Estados por efecto de sus normas constitucionales. 
El criterio de competencia surge frente a la insuficiencia del criterio de jerarquía para solucionar los conflictos normativos: cuando existen normas de igual jerarquía normativa -como es el caso de la sanción de inhabilidad- este es insuficiente; de otro lado, cuando la relación es de horizontalidad, en el marco de competencias exclusivas o preferentes, "sobre el presupuesto de que cada una es competente en un respectivo y bien delimitado ámbito de materias, esta colisión jerárquica es imposible" (Garronera Morales, 2011). Este criterio puede trasladarse también al ejercicio judicial de interpretación normativa, como uno coadyuvante al principio pro homine, estableciendo quién tendrá la interpretación preferente de dicha norma.

En ese hilar de ideas se origina una primacía de la $\mathrm{CADH}$ y de la Corte IDH respecto a todo lo que verse sobre su competencia normativa; esto no pugna con el principio de supremacía constitucional por cuanto "la supremacía implicaría jerarquía y, en cambio, la primacía no, ya que esta supone simple prevalencia de la norma que la posee en un ámbito determinado y porque la constitución así lo autoriza" (Garronera Morales, 2011), generándose así un criterio hermenéutico sustancial que permite indicar que es desde la CADH que se debe dar solución a la tensión normativa.

\section{CONCLUSIONES}

La Constitución, como norma suprema, determina criterios hermenéuticos para estructurar un sistema normativo; estos permiten a los ope- radores jurídicos solucionar vacíos o colisiones normativas. De igual modo, dentro del sistema de fuentes, se encuentran las fuentes del derecho internacional que otorgan criterios respecto de los instrumentos internacionales, y desarroIlan, en especial, los catálogos de derechos allí contenidos. En ese sentido, el Estado colombiano a través de la figura del bloque de constitucionalidad ha otorgado el carácter de fuente normativa a los tratados sobre derechos humanos, ubicándolos al mismo nivel de la Constitución; esto con el fin de garantizar la eficacia en la satisfacción de derechos humanos a través de un medio de control. En relación con lo anterior, dentro del panorama del derecho internacional, la doctrina del control de convencionalidad se consolida como una herramienta que ofrece garantías en relación con el respeto por los derechos fundamentales, la preeminencia del derecho y los principios del Estado democrático.

En ese orden de ideas, se puede concluir que este control plantea cambios significativos en la concepción jurídica de las fuentes del derecho dentro de los Estados constitucionales, ya que dicha doctrina da a entender que la CADH es superior a las normas de jerarquía constitucional; en consecuencia, debido a la faceta destructiva del control de convencionalidad, la soberanía de un Estado se vería afectada.

De igual forma, se estudió la sanción de inhabilidad como un conflicto normativo que por su fuerza explicativa permitió comprender el fenómeno, dilucidando que dentro del orden jurídico colombiano el régimen de la responsabilidad de los funcionarios públicos constituye garantía del 
correcto desenvolvimiento de la función pública, donde la sanción de inhabilidad representa una herramienta para reparar el ejercicio incorrecto de la función administrativa. Esta sanción es limitada por la legalidad, ya que se establecen requisitos procedimentales y argumentativos para su imposición. Por el contrario, en la CADH, la concepción de la naturaleza jurídica de la sanción de inhabilidad no es afín a los postulados del orden jurídico colombiano.

A pesar de las interpretaciones que la Corte Constitucional ha hecho al respecto, se puede concluir que, en relación con el régimen de la sanción de inhabilidad, el Estado colombiano está violando la CADH; esto implicaría, en primer lugar, que la sanción de inhabilidad desde la potestad disciplinaria del Estado es inconvencional $y$, en segundo lugar, que el Estado colombiano sea declarado responsable internacionalmente por violación a la Convención.

Frente a esto, el principio de primacía del derecho internacional y de competencia normativa plantea una solución útil para resolver la tensión producida entre la normatividad interna y externa. Es por ello que, para el caso de la sanción de inhabilidad en el ordenamiento jurídico colombiano, tal principio debe ser adaptado específicamente con relación al sistema interamericano de derechos humanos. Dicho criterio sería coadyuvante al principio pro homine, y permitiría establecer que la CADH y la interpretación que hace de esta la Corte IDH constituyen la norma y la respectiva interpretación más favorable a la persona humana; todo esto sin que se afecte el principio de supremacía constitucional.
Partiendo de la primacía de la Convención, frente al caso específico estudiado se pueden proponer como soluciones las medidas adoptadas por los Estados en relación con la vinculatoriedad de la CADH y las sentencias de la Corte IDH. Estas van desde reformas constitucionales, emisión de leyes que regulen la ejecución de las sentencias, hasta la declaración de una sentencia de la Corte IDH como inejecutable y la denuncia del tratado. Costa Rica, por ejemplo, estableció leyes que regulan la fuerza ejecutiva de las sentencias, al igual que Colombia, que pese a haberlas determinado para unos cuantos órganos colegiados no ha sido reacia a cumplir con las órdenes de la Corte IDH. Perú, en cambio, desde su texto constitucional y código de procedimiento constitucional estableció su fuerza ejecutiva (Ventura López, 2009). En países como México se adoptaron reformas constitucionales que les permitieron dar paso a legislar una ley de reparación (Rangel Hernández, 2011). Todas estas propuestas pueden cimentarse en el principio de competencia, como marco constitucional para la eficacia normativa de la CADH.

Respecto a la sanción de inhabilidad, la solución podría establecerse desde la instauración de jueces penales competentes para observar el comportamiento de los funcionarios públicos y castigar sus irregularidades - lo cual afectaría la función pública pues no todos los comportamientos disciplinariamente relevantes lo son penalmente- hasta un replanteamiento del sistema procedimental de la Procuraduría, de uno inquisitivo a otro acusatorio, que hipotéticamente, a través de la competencia consultiva la Corte IDH se encontrara ajustado a la CADH. 
Como solución fatalista, contraria a la teleología estatal, se podría, como en Venezuela, denunciar el tratado y retirar la vigencia que tiene tanto la CADH como la Corte IDH para regular de forma preferente la materia de los DD. HH., esto si el ordenamiento colombiano no está dispuesto a cumplir sus obligaciones válidamente adquiridas.

\section{Referencias}

Administration des Finances de l'Etat contra Sociedad Anónima Simmenthal, asunto 106/77, Rec. p. 629. Tribunal de Justicia de la Comunidades Europeas (marzo 9, 1978).

Aguiló Regla, J. (2000). Teoría general de las fuentes del Derecho (y del orden jurídico). Barcelona: Ariel.

Alegre Martínez, M. Á. (1994). La primacía del derecho comunitario sobre el ordenamiento jurídico estatal: aspectos constitucionales. Revista de Derecho Político, (38), 93-173.

Almonacid Arellano y otros vs. Chile. Serie C . $^{\circ}$ 154. Corte Interamericana de Derechos Humanos (septiembre 26, 2006).

Amaya, Á. (Junio de 2005). El principio pro homine: interpretación extensiva vs. el consentimiento del Estado. International Law: Revista Colombiana de Derecho Internacional, (5), 337-380.

Asamblea Nacional Constituyente. (1991). Constitución Política de Colombia.
Barragán, M. (2013). Los principios constitucionales fundamentales en la gestión contractual de las entidades públicas. Su naturaleza jurídica y la determinación jurisprudencial de su contenido y alcance normativo. [Tesis de maestría inédita. Universidad Industrial de Santander, Bucaramanga, Colombia].

Brewer-Carías, A. R. y Santofimio Gamboa, J. O. (2013). Control de convencionalidad y responsabilidad del Estado. Bogotá: Universidad Externado de Colombia.

Bustillo Marín, R. (2011). Líneas jurisprudenciales. El control de convencionalidad: la idea del bloque de constitucionalidad y su relación con el control de constitucionalidad en materia electoral. Mexico: Tribunal Electoral del Poder Judicial de la Federación.

Caso "La última tentación de Cristo" (Olmedo Bustos y otros vs. Chile). Serie C n. ${ }^{\circ}$ 73. Corte Interamericana de Derechos Humanos (febrero 5,2001$)$.

Corte Constitucional de Colombia. Sentencia C-1090 de 2003. Expediente D-4626. (M. P.: Clara Inés Vargas Hernández: noviembre 19 de 2003).

Corte Constitucional de Colombia. Sentencia C-028 de 2006. Expediente D-5768. (M. P.: Humberto Antonio Sierra Porto: enero 26 de 2006).

Corte Constitucional de Colombia. Sentencia C-941 de 2010. Expediente LAT-360. (M. P.: 
Jorge Iván Palacio Palacio: noviembre de 24 de 2010).

Corte Constitucional de Colombia. Sentencia C-442 de 2011. Expediente D-8295. (M. P.: Humberto Antonio Sierra Porto: 25 de mayo de 2011).

Corte Interamericana de Derechos Humanos. (2005). Un cuarto de siglo: 1979-2004. San José de Costa Rica: CIDH.

Ferrer Mac-Gregor, E. (2010). El Control Difuso de Convencionalidad en el Estado Constitucional. Mexico: UNAM.

Flaminio Costa contra E.N.E.L., 6-64. Tribunal de Justicia de las Comunidades Europeas (julio 15,1964$)$.

García Sayán, D. (2009). La recepción nacional del derecho internacional de los derechos humanos y de la jurisprudencia de la Corte Interamericana de Derechos Humanos. En S. García Ramírez, Recepción nacional del derecho internacional de los derechos humanos y admisión de la competencia contenciosa de la corte interamericana. México: unAm.

Garrorena Morales, Á. (2011). Derecho Constitucional. Teoría de la Constitución y sistema de fuentes. Madrid: Centro de Estudios Políticos y Constitucionales.

Gómez Pavajeau, A. (2011). Dogmática del derecho disciplinario (Quinta ed.). Bogotá: Universidad Externado de Colombia.
Hitters, J. C. (2009). Control de constitucionalidad y control de convencionalidad. Comparación. (Criterios fijados por la Corte Interamericana de Derechos Humanos). Estudios constitucionales, VII, 109-128.

Jinesta, E. (2012). Control de convencionalidad ejercido por los tribunales y salas constitucionales. En E. Ferrer Mac-Gregor (Coord.), El control difuso de convencionalidad. México: Fundación Universitaria de Derecho, Administración y Política.

Lori Berenson Mejía vs. Perú. Serie C n. 134. Corte Interamericana de Derechos Humanos (noviembre 25, 2004).

Masacre de Mapiripán vs. Colombia. Serie C n. ${ }^{\circ}$ 134. Corte Interamericana de Derechos Humanos (septiembre 15, 2005).

Mejía Quintana, O. (2005). Teoría política, democracia radical y filosofía del derecho: legitimidad, validez y eficacia en el pensamiento contemporáneo. Bogotá: Temis.

Nieto, A. (1994). Derecho administrativo sancionador (Segunda ed.). Madrid: Tecnos.

Noguera, H. (2011). Informe pericial caso López Mendoza vs. Venezuela. Estudios Constitucionales, (1), 339-362.

Oficina de las Naciones Unidas contra la Droga y el Delito. (2010). Guía técnica de la Convención de la Naciones Unidas contra la corrupción. Viena: Autor. 
Organización de las Naciones Unidas. (1945). Estatuto de la Corte Internacional de Justicia.

Organización de las Naciones Unidas. (23 de mayo de 1969). Convención de Viena sobre el derecho de los tratados.

Organización de los Estados Americanos. (7 al 22 de noviembre de 1969). Convención Americana sobre Derechos Humanos.

Pinto, M. (1997). El principio pro homine. Criterios de hermenéutica y pautas para la regulación de los derechos humanos. En M. Abregú y C. Courtis (Edits.), La aplicación de los tratados de derechos humanos por los tribunales locales (págs. 163-171). Buenos Aires: Centro de Estudios Legales y Sociales (CELS)/Editores del Puerto.

Quinche Ramírez, M. (Julio-diciembre de 2009). El control de convencionalidad y el sistema colombiano. Revista Iberoamericana de Derecho Procesal Constitucional (12), 163-190.

Rangel Hernández, L. (Julio-diciembre, 2011). Sentencias condenatorias al Estado mexicano dictadas por la Corte Interamericana de Derechos Humanos y sus implicaciones en el orden jurídico nacional. Obtenido de: http:// www.scielo.org. $\mathrm{mx} /$ scielo.php?pid=S187021472011000200008\&script=sci_arttext

Ross, A., Muñoz de Baena, J. L., Prada García, A. y López Pietsch, P. (2007). Teoría de las fuentes del derecho: (una contribución a la teoría del derecho positivo sobre la base de investi- gaciones histórico-dogmáticas). Madrid: Centro de Estudios Políticos y Constitucionales.

Sagües, N. P. (2010). Obligaciones internacionales y control de convencionalidad. Estudios Constitucionales, (1), 117-136.

Trabajadores Cesados del Congreso (Aguado Alaro y otros) vs. Perú. Serie C n. ${ }^{\circ}$ 158. Corte Interamericana de Derechos Humanos (noviembre 24, 2006).

Trayter, J. M. (1992). Manual de derecho disciplinario de los funcionarios públicos. Madrid: Marcial Pons, Ediciones Jurídicas/[Catalunya]: Generalitat de Catalunya, Escola d`Administració Pública de Catalunya.

Ventura López, M. E. (29 de septiembre de 2009). La ejecución de las sentencias de la Corte Interamericana de Derechos Humanos por parte de los tribunales nacionales. Obtenido de: http://sitios.poder-judicial.go.cr/salaconstitucional/articulos\%20y\%20conferencias/Seminario_20aniversario/006.pdf

Witker, J. (Mayo-Agosto, 2008). Hacia una investigación jurídica integrativa. Boletin Mexicano de Derecho Comparado, xLI(122), 943-964.

Zaffaroni, E. y Risso, G. (s.f.). Inhabilitación y juicio político en Argentina. Obtenido de unam: www.juridicas.unam.mx: http://biblio.juridicas.unam.mx/libros/6/2553/29.pdf 